\title{
Corrosion Performance of Cu-Based Coins in Artificial Sweat
}

\author{
J. Porcayo-Calderon, ${ }^{1,2}$ R. A. Rodríguez-Díaz, ${ }^{3}$ E. Porcayo-Palafox, ${ }^{1}$ \\ and L. Martinez-Gomez ${ }^{2,4}$ \\ ${ }^{1}$ CIICAp, Universidad Autónoma del Estado de Morelos, Avenida Universidad 1001, 62209 Cuernavaca, MOR, Mexico \\ ${ }^{2}$ Instituto de Ciencias Físicas, Universidad Nacional Autónoma de México, Avenida Universidad s/n, 62210 Cuernavaca, MOR, Mexico \\ ${ }^{3}$ Universidad Politécnica del Estado de Morelos, Boulevard Cuauhnahuac 566, Col. Lomas del Texcal, 62574 Jiutepec, MOR, Mexico \\ ${ }^{4}$ Corrosion y Protección (CyP), Buffon 46, 11590 Mexico City, Mexico
}

Correspondence should be addressed to J. Porcayo-Calderon; jporcayoc@gmail.com

Received 8 July 2016; Revised 6 October 2016; Accepted 20 October 2016

Academic Editor: Stefano Caporali

Copyright (C) 2016 J. Porcayo-Calderon et al. This is an open access article distributed under the Creative Commons Attribution License, which permits unrestricted use, distribution, and reproduction in any medium, provided the original work is properly cited.

\begin{abstract}
The performance of different $\mathrm{Cu}$-based coins in artificial sweat was evaluated. The electrochemical behavior of the coins was determined by potentiodynamic polarization curves, linear polarization resistance, and electrochemical impedance spectroscopy. Regardless of the chemical composition of the $\mathrm{Cu}$-based coins, they showed similar polarization curves; particularly, the observed similarity in the anodic zone suggests that the corrosion mechanism is the same in all cases. The presence of $\mathrm{Ni}$ and $\mathrm{Zn}$ does not appreciably affect the corrosion resistance of $\mathrm{Cu}$. However, the presence of both elements affects the corrosion resistance of $\mathrm{Cu}$. Electrochemical impedance spectroscopy measurements showed the presence of three time constants with very similar characteristics, again indicating that the main corrosion mechanism is the same in all cases. Equivalent circuits confirmed that the corrosion performance of the $\mathrm{Ni}-\mathrm{Zn}-\mathrm{Cu}$ coins depends on the $\mathrm{Zn} / \mathrm{Ni}$ ratio, such that decreasing this value decreases the corrosion resistance of the alloy. In general, nickel has a detrimental effect due to the formation of highly soluble Ni-based corrosion products.
\end{abstract}

\section{Introduction}

Metallic corrosion originated by metal alloys in contact with human body has been assessed and studied in various researches. Frequently this problem is associated with the tarnishing of the metals as a consequence of the contact of the sweat generated by some parts of human body in contact with pieces of metals or alloys such as coins, jewels, piercing, and earrings. The contact of metals with human sweat can produce undesirable effects. The problem of the metallic corrosion resulting from the formation of corrosion products or liberation of metallic ions originated by the palmar sweat is typical to a great number of industrial occupations [1].

Besides the tarnishing that occurs in metals when exposed to artificial sweat, another aspect concerning human health, which cannot be disregarded, is the detrimental effects on human body that could induce the metal contact with human body. Metallic objects in long periods of contact with human skin may, in fact, produce a toxic effect usually attributed to the release of metal ions. For example, dermal hypersensitivity to $\mathrm{Ni}$ or $\mathrm{Ni}$-based alloys is typical. In this case, contact dermatitis is not originated by nickel itself but by the nickel salts which are formed as a result of the contact of human sweat with a metallic object, for example, a necklace, ring, or watch. This phenomenon is developed simultaneously with the corrosion of the object. Once a person acquired nickel allergy, this illness lasts for life [2]. The metallic corrosion induced by human sweat has been known since a century approximately. Various researchers have stated that metals such as $\mathrm{Mg}, \mathrm{Ni}$, and stainless steels have experienced pitting and crevice corrosion and hence must be protected with appropriate passive layers for a better performance in service [3].

Human sweat is constituted of greatly variable quantities of primary electrolytes, organic acids and carbohydrates, ionic constituents, nitrogenous substances, amino acids, and vitamins and miscellaneous constituents. Sweat is composed of $99.0-99.5 \%$ water and $0.5-1.0 \%$ solids. The published literature describing synthetic sweat formulations is diverse and includes many different compounds. All of the published 
synthetic formulas differ in composition, concentration, and $\mathrm{pH}$. Although there have been few reports concerning the allergy induced by cooper, recently this element has been increasingly recognized as an allergen. Despite the fact that $\mathrm{Cu}$ shows allergenic potential lower than the other metals, the allergy induced by this element has an undoubtful clinical importance. Corrosion studies of copper alloys in artificial sweat and in Ringer biological solution showed that, at low potentials, a thin oxide layer was produced but, at nobler potentials, a thick chloride or oxychloride layer was originated. The composition and thickness of the surface layers depended on the stability of complexes of the metal ions with the chloride ions and with the complexing agents present in the artificial sweat. The corrosion products were formed simultaneously with an increment of the dissolution rate of zinc and nickel, and this behavior augmented the allergen problem of nickel in contact with human skin [4-6].

Corrosion of the coins is a common phenomenon during the circulation process, which shortens its service life and reduces its collectable value. Coins come into contact with the skin during the usage process, and sweat left on them becomes a major reason for their tarnishing [7]. A lot of the current coins consist of a ring and an inner pill, and the bimetallic structure of these coins can be a problem because of the metallic enrichment of both pill and ring surfaces [5]. Due to prolonged contact with human skin, the metal dissolution is important because of potential allergic reactions [6].

Therefore, the purpose of this study is to evaluate the corrosion behavior of $\mathrm{Cu}$-based coins in artificial sweat. The electrochemical performance of the coins was determined by potentiodynamic polarization curves, linear polarization resistance, and electrochemical impedance spectroscopy.

\section{Experimental Procedure}

A batch of $20 \mathrm{Cu}$-based coins from different countries was corrosion tested by means of electrochemical techniques. However, because in many cases the nominal chemical composition reported does not correspond to the actual chemical composition [8], it was decided to determine the elemental chemical composition by EDS (Energy Dispersive Spectroscopy) technique. Therefore, for electrochemical tests, only the coins with the chemical composition reported in Table 1 were selected. In addition, high-purity copper (99.99 wt.\%) (Goodfellow) was evaluated for comparison purposes. The coins consisted of binary, ternary, and quaternary alloy systems, and, for analysis purposes, the alloys only will be referred to by the percentage of alloying elements. In general, Ni-Zn-Cu alloys are known as Alpaca, German Silver, Nickel Bronze, or Nickel Silver, and the Cu6Zn5AllSn alloy is known as Nordic Gold.

Coins were cut into rectangular form in order to be used as electrode work. They were spot-welded to a $\mathrm{Cu}$ wire and then mounted in polyester resin. In this state, the coins were abraded with emery paper down to $1200 \mathrm{SiC}$, and once the surface of the specimens was metallographically prepared,
TABLE 1: Chemical composition of the Cu-based coins (wt.\%).

\begin{tabular}{lcccccc}
\hline Alloy & $\mathrm{Ni}$ & $\mathrm{Zn}$ & $\mathrm{Al}$ & $\mathrm{Mn}$ & $\mathrm{Sn}$ & $\mathrm{Cu}$ \\
\hline $\mathrm{Cu}$ & $<0.01$ & $<0.01$ & $<0.01$ & $<0.01$ & $<0.01$ & 99.99 \\
$23 \mathrm{Ni}$ & 23.0 & - & - & - & - & $\mathrm{Bal}$ \\
$32 \mathrm{Zn}$ & - & 31.5 & - & - & - & $\mathrm{Bal}$ \\
$10 \mathrm{Ni} 25 \mathrm{Zn}$ & 9.7 & 25.5 & - & - & - & $\mathrm{Bal}$ \\
$13 \mathrm{Ni17Zn}$ & 13.0 & 17.0 & - & - & - & $\mathrm{Bal}$ \\
$15 \mathrm{Ni} 22 \mathrm{Zn}$ & 14.5 & 22.0 & - & - & - & $\mathrm{Bal}$ \\
8Ni27Zn & 8.5 & 27.0 & - & - & - & $\mathrm{Bal}$ \\
$6 \mathrm{Al} 2 \mathrm{Ni}$ & 2.0 & - & 6.0 & - & - & $\mathrm{Bal}$ \\
$13 Z n 6 \mathrm{Mn} 4 \mathrm{Ni}$ & 3.6 & 13.3 & - & 6.0 & - & $\mathrm{Bal}$ \\
$6 Z n 5 \mathrm{Zl1Sn}$ & - & 6.0 & 5.5 & - & 1.2 & $\mathrm{Bal}$ \\
\hline
\end{tabular}

TABLE 2: Chemical composition of artificial sweat ( $\mathrm{pH}$ adjusted to 4.7 by $\mathrm{NaOH})$.

\begin{tabular}{lc}
\hline Compound & Content $[\mathrm{g} / \mathrm{L}]$ \\
\hline $\mathrm{NaCl}$ & 20.0 \\
$\mathrm{NH}_{4} \mathrm{Cl}$ & 17.5 \\
Acetic acid & 5.0 \\
Lactic acid & 15.0 \\
\hline
\end{tabular}

samples were washed with distilled water and then by ethanol in an ultrasonic bath for 10 minutes.

Corrosive electrolyte used for the electrochemical essays was a synthetic sweat solution which was prepared according to ISO 3160-2 standard [9]. Table 2 shows the chemical composition of the artificial sweat.

Electrochemical tests were performed in a Gamry Interface 1000 Potentiostat controlled by a personal computer and the Framework ${ }^{\mathrm{TM}}$ data acquisition software version 7.03. Experiments were performed in a three-electrode electrochemical cell (working electrode, saturated calomel electrode (SCE) as the reference electrode, and a high-purity graphite rod as the auxiliary electrode). In order to obtain the potentiodynamic polarization curves, coins were polarized from $-400 \mathrm{mV}$ to $800 \mathrm{mV}$ from $E_{\text {corr }}$ value at a scan rate of $1 \mathrm{mV} / \mathrm{s}$. From potentiodynamic polarization curves the values of corrosion potential $\left(E_{\text {corr }}\right)$, current density $\left(I_{\text {corr }}\right)$, and Tafel slopes $(b a, b c)$ were determined. Before starting the test, the system was allowed to stabilize for a period of 0.5 hours. For the purpose of obtaining the values of polarization resistance $R_{p}$, the linear polarization resistance (LPR) was measured within the interval of $\pm 20 \mathrm{mV}$ from $E_{\text {corr }}$ value with a scan rate of $1 \mathrm{mV} / \mathrm{s}$. After determining $R_{p}$ value, the corrosion current density $\left(I_{\text {corr }}\right)$ was calculated by applying the Stern-Geary equation.

$$
I_{\text {corr }}=\frac{b \mathrm{a} b \mathrm{c}}{2.303 R_{p}(b \mathrm{a}+b \mathrm{c})} .
$$

Measurements of electrochemical impedance spectroscopy (EIS) were performed in the frequency range of $0.01 \mathrm{~Hz}$ to $100,000 \mathrm{~Hz}$ with a perturbation of $\pm 10 \mathrm{mV}$. In each test performed a new working electrode was used. The tests were performed in triplicate and the values reported are the average of the values obtained. 
TABLE 3: Electrochemical parameters of the Cu-based coins evaluated in artificial sweat at $37^{\circ} \mathrm{C}$.

\begin{tabular}{|c|c|c|c|c|c|c|}
\hline Alloy & $\begin{array}{l}E_{\text {corr }} \\
(\mathrm{mV})\end{array}$ & $\begin{array}{c}b \mathrm{a} \\
(\mathrm{mV} / \mathrm{Dec})\end{array}$ & $\begin{array}{c}b c \\
(\mathrm{mV} / \mathrm{Dec})\end{array}$ & $\begin{array}{c}I_{\text {corr }} \\
\left(\mathrm{mA} / \mathrm{cm}^{2}\right)\end{array}$ & $\begin{array}{c}R_{p} \\
\left(\mathrm{Ohms}-\mathrm{cm}^{2}\right)\end{array}$ & $\begin{array}{l}\mathrm{Zn} / \mathrm{Ni} \\
\text { ratio }\end{array}$ \\
\hline $\mathrm{Cu}$ & -310 & 300 & 69 & 0.01110 & 2276 & - \\
\hline $23 \mathrm{Ni}$ & -285 & 207 & 67 & 0.00734 & 3085 & - \\
\hline $32 \mathrm{Zn}$ & -347 & 355 & 67 & 0.00854 & 2950 & - \\
\hline $10 \mathrm{Ni} 25 \mathrm{Zn}$ & -332 & 334 & 72 & 0.00941 & 3298 & 2.5 \\
\hline 13Nil7Zn & -301 & 343 & 62 & 0.00810 & 3236 & 1.3 \\
\hline $15 \mathrm{Ni} 22 \mathrm{Zn}$ & -323 & 230 & 58 & 0.00573 & 2900 & 1.47 \\
\hline $8 \mathrm{Ni} 27 \mathrm{Zn}$ & -271 & 330 & 75 & 0.00406 & 4880 & 3.37 \\
\hline $6 \mathrm{Al} 2 \mathrm{Ni}$ & -344 & 244 & 70 & 0.00624 & 4708 & - \\
\hline 13Zn6Mn4Ni & -346 & 333 & 68 & 0.00724 & 3350 & 3.25 \\
\hline 6Zn5Al1Sn & -360 & 195 & 61 & 0.00362 & 4152 & - \\
\hline
\end{tabular}

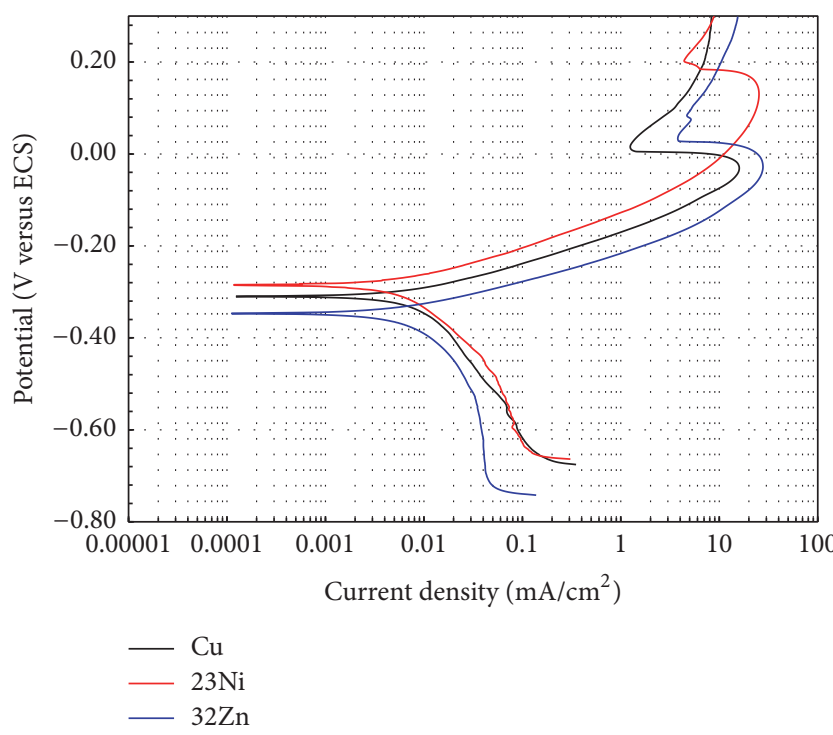

Figure 1: Polarization curves for the Cu-based binary alloys in artificial sweat at $37^{\circ} \mathrm{C}(d E / d t=1.0 \mathrm{mV} / \mathrm{s})$.

\section{Results and Discussion}

3.1. Potentiodynamic Polarization Curves. The polarization curves for $\mathrm{Cu}$ and binary alloys are displayed in Figure 1. The polarization curves for pure copper and binary alloys exhibited similar active-passive behavior; similar observations have been reported by other authors [5]. The addition of $\mathrm{Ni}$ and $\mathrm{Zn}$ to the copper generated a diminution of the corrosion rate; however, the $\mathrm{Ni}$ induces a shift of the corrosion potential towards the noble side and the $\mathrm{Zn}$ addition conversely. Also, $\mathrm{Cu}$ and $32 \mathrm{Zn}$ alloy showed a more defined passivation zone compared to $23 \mathrm{Ni}$ alloy, and they are passivated at lower overpotentials. The potentiodynamic behaviors of pure copper and the ternary alloys are presented in Figure 2. The variation in the composition of the coins influences the polarization and the passivation nature. The addition of both $\mathrm{Ni}$ and $\mathrm{Zn}$ induces a decrease of corrosion rate; however it seems that this decrease is dependent on the $\mathrm{Zn} / \mathrm{Ni}$ ratio. Figure 3 shows the polarization curves for pure

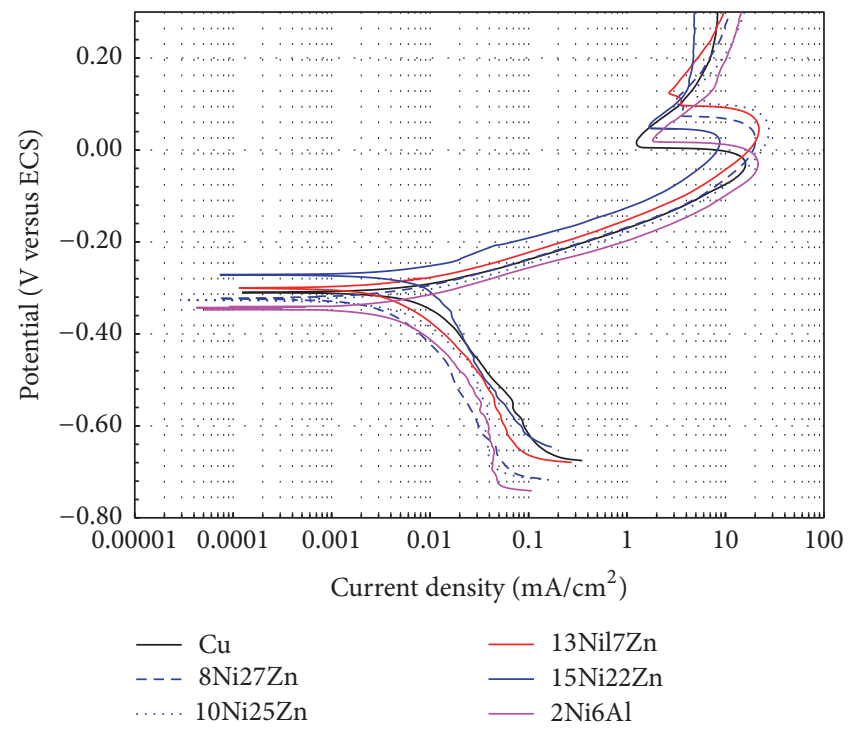

Figure 2: Polarization curves for the Cu-based ternary alloys in artificial sweat at $37^{\circ} \mathrm{C}(d E / d t=1.0 \mathrm{mV} / \mathrm{s})$.

$\mathrm{Cu}$ together with the quaternary alloys. The anodic branch of $\mathrm{Cu}$ and quaternary alloys exhibits an active-passive behavior. Similarly to the polarization behavior of ternary alloys, the addition of the groups of triad elements, $\mathrm{Zn}$-Al-Sn and $\mathrm{Zn}$ $\mathrm{Mn}-\mathrm{Ni}$, to the pure $\mathrm{Cu}$, induced a diminution of its corrosion rate. It is worth noticing that the quaternary $\mathrm{Cu}-\mathrm{Zn}-\mathrm{Al}-\mathrm{Sn}$ alloys exhibited the lowest corrosion rate.

Table 3 shows the electrochemical parameters of the $\mathrm{Cu}$-based coins determined from polarization curves in the region of $\pm 250 \mathrm{mV}$ with respect to corrosion potential. Importantly, all tested coins show a similar anodic-cathodic behavior, with possible significant variations at overpotentials above 0 volts. The low value of the anodic slopes $(60-70 \mathrm{mV})$ suggests a process of active dissolution due to the formation of soluble species $\left(\mathrm{CuCl}_{2}{ }^{-}\right)$, and, on the other hand, the presence of the passive region is due to the $\mathrm{Cu}_{2} \mathrm{O}$ formation as other authors have suggested [5]. The observed similarity in the anodic zone at potentials above $E_{\text {corr }}$ value (up to $300 \mathrm{mV}$ ) suggests that the main corrosion mechanism is the same in all 


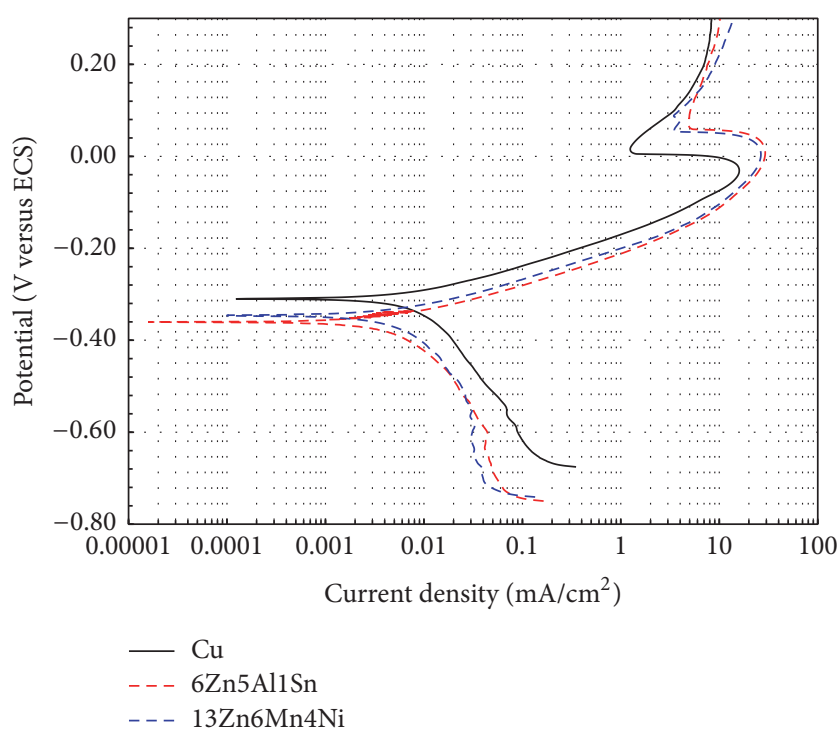

FIgURE 3: Polarization curves for the $\mathrm{Cu}$-based quaternary alloys in artificial sweat at $37^{\circ} \mathrm{C}(d E / d t=1.0 \mathrm{mV} / \mathrm{s})$.

cases. Regardless of the number of alloying elements, various studies on copper-based alloys in artificial sweat confirm this assertion $[4-7,10,11]$, such that the main corrosion product detected is the cuprous oxide $\left(\mathrm{Cu}_{2} \mathrm{O}\right)$, besides copper chloride hydroxide $\left(\mathrm{Cu}_{2}(\mathrm{OH})_{3} \mathrm{Cl}\right)$. This confirms that the sodium chloride $(\mathrm{NaCl})$ present in the artificial sweat accelerates the anodic reaction process.

3.2. Linear Polarization Resistance Curves. The variation of corrosion rate in terms of $I_{\text {corr }}$ as a function of the immersion time for pure copper together with the binary, ternary, and quaternary alloys exposed to artificial sweat is presented in Figure 4 . $I_{\text {corr }}$ values were obtained from the Stern-Geary equation, Tafel slopes (from polarization curves), and $R_{p}$ values. It can be seen that the alloy $15 \mathrm{Ni} 22 \mathrm{Zn}$ displayed the highest corrosion rate after the two hours of exposure, while the $13 \mathrm{Zn} 6 \mathrm{Mn} 4 \mathrm{Ni}$ and $6 \mathrm{Zn} 5 \mathrm{Al} 1 \mathrm{Sn}$ exhibited the lower corrosion rate in terms of $I_{\text {corr }}$, besides the fact that the corrosion current density of these quaternary alloys remained almost constant during the 24 hours of immersion. Also, the corrosion rate of $\mathrm{Cu}$ tended to prevail more or less constantly during the whole exposure period. Besides, it is worth noticing that pure copper exhibited a lower corrosion rate than the binary and ternary alloys during the lapse of time from around the 8th hour of exposure up to the end of the linear polarization test. The fact that the corrosion rate of $\mathrm{Cu}$ remained more or less constant for 24 hours can be certainly related to the good stability of the $\mathrm{Cu}_{2} \mathrm{O}$ passive film formed onto copper surface. It can be observed that the behavior of binary alloys was very similar to that of copper; this may indicate that in long exposures the presence of $\mathrm{Ni}$ and $\mathrm{Zn}$ does not appreciably affect the corrosion resistance of $\mathrm{Cu}$. However, in the case of ternary alloys the presence of both elements affects the corrosion resistance of $\mathrm{Cu}$, apparently at higher nickel content, and the corrosion rate is increased. Also, corrosion rate of binary and ternary

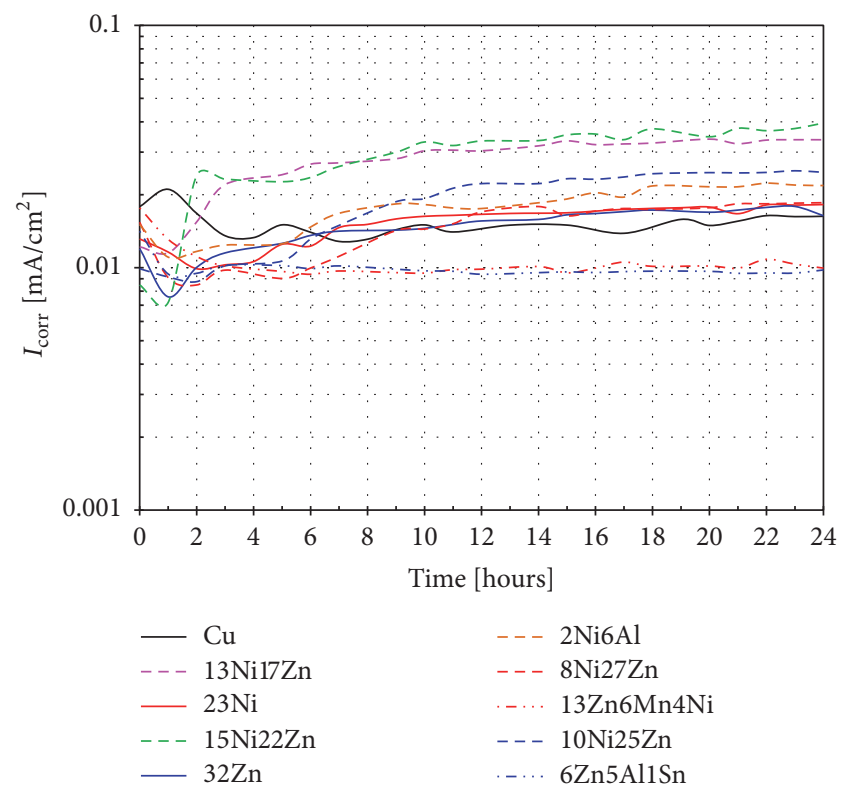

FIgURE 4: Change of $I_{\text {corr }}$ values with time for Cu-based coins evaluated in artificial sweat at $37^{\circ} \mathrm{C}$.

alloys increased while the exposure time had elapsed. This trend could be ascribed to the detrimental effect induced in the protective nature of the copper oxide formed on surface of materials. Specifically, the formation of $\mathrm{NiO}$ and $\mathrm{ZnO}$ could have produced a reduction of the protective character of the passive film formed on the surface of the alloys. In this sense, Milošev and Kosec [4] studied the nickel ion release associated with nickel allergy which was released by the Cu18Ni20Zn alloy after an immersion period in artificial sweat solution for 30 days. In this research, the authors reported that the surface layer of the alloy was constituted predominantly by $\mathrm{Cu}_{2} \mathrm{O}$, but the presence of $\mathrm{NiO}$ and $\mathrm{ZnO}$ also was detected; on the other hand, they also found that the Ni concentration into electrolyte is two times higher than that of $\mathrm{Cu}$ and $\mathrm{Zn}$, while the concentrations of $\mathrm{Cu}$ and $\mathrm{Zn}$ were similar, this being due to the formation of Ni-based corrosion products being highly soluble. This may also explain the poor performance of the $2 \mathrm{Ni} 6 \mathrm{Al}$ ternary alloy, on one hand the presence of nickel may form soluble corrosion products, and, on the other hand, the formation of aluminum oxide provides little protection because of its low stability in halides-rich electrolytes $[12,13]$.

3.3. EIS Measurements. Impedance spectra for copper and bimetallic alloys after 24 hours of immersion in artificial sweat at $37^{\circ} \mathrm{C}$ are shown in Figure 5. The analysis of the Nyquist plot shows very similar characteristics for copper and bimetallic alloys, namely, the apparent presence of a capacitive semicircle and the formation of a "tail" of scattered points in the low frequency region, where this scattering may correspond to processes of either diffusion or adsorption of species. Generally the information provided or interpreted from the analysis of the Nyquist plot is limited and can lead to erroneous conclusions, this being mainly because it is impossible to define the frequency range where the surface 

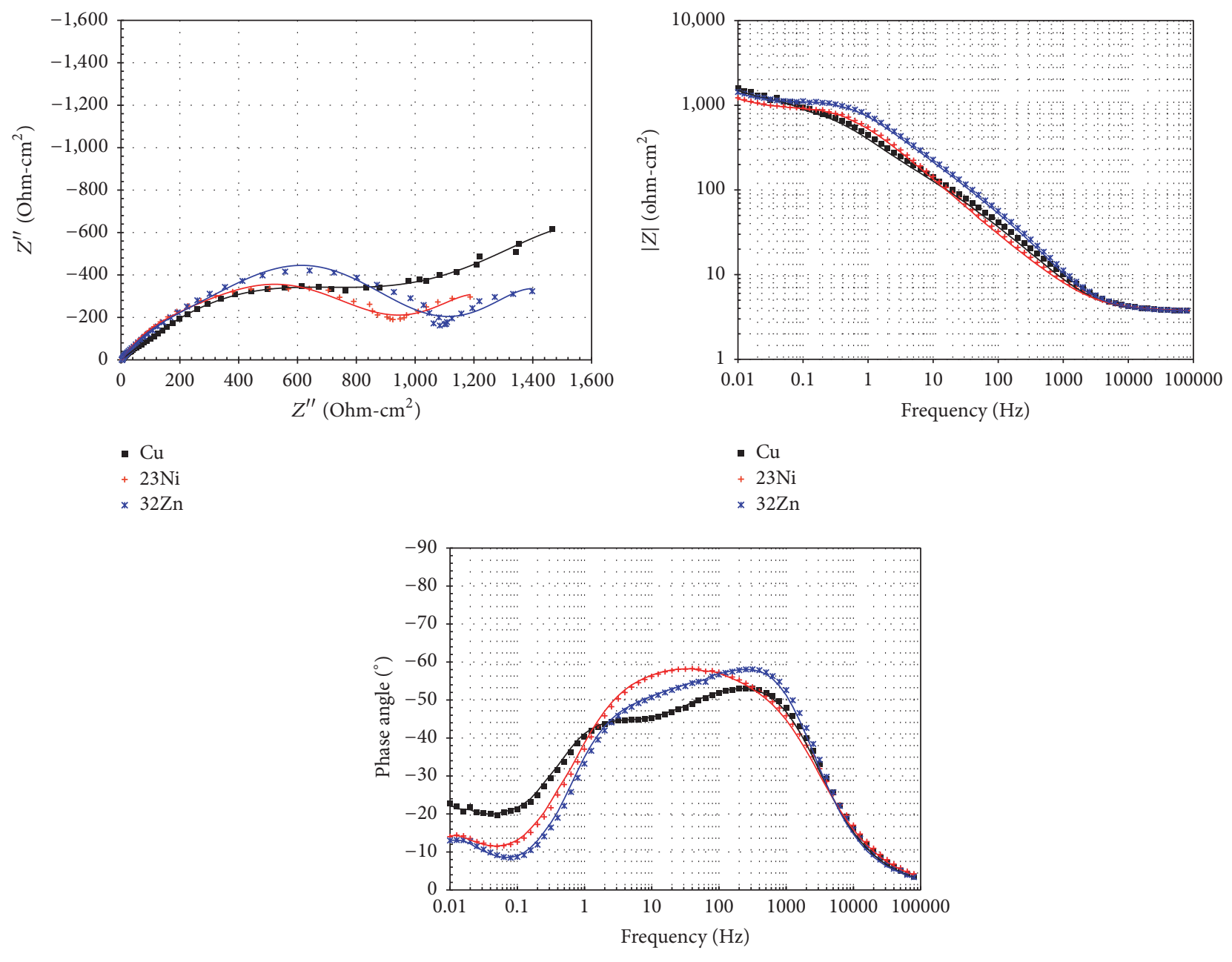

$$
\begin{aligned}
& \text { - } \mathrm{Cu} \\
& +23 \mathrm{Ni} \\
& \text { * } 32 \mathrm{Zn}
\end{aligned}
$$

Figure 5: Nyquist and Bode plots for the $\mathrm{Cu}$-based binary alloys in artificial sweat at $37^{\circ} \mathrm{C}$ after 24 hours. Points are the experimental data, and the continuous lines are the fitting data.

phenomena are occurring [13-15]. It is therefore important to perform a complete analysis of impedance spectra, that is, taking into account the Bode plots. Furthermore, analysis of the Bode plot is simpler because the dispersion of the experimental data is minimized and the analysis can be performed by frequency range. In particular, the phase angle-frequency relationship clearly indicates how many time constants exist in the system under analysis, and this is impossible to observe from the analysis of the Nyquist plot, especially in the high frequency region. Bode diagrams can be analyzed for frequency ranges, regions of high, intermediate, and low frequency [13-17]. In the high frequency region ( $1 \mathrm{k}-$ $100 \mathrm{kHz}$ ), Bode plot shows a horizontal line (high frequency plateau) with the phase angle approaching $0^{\circ}$. This fingerprint is the characteristic response of the electrolytic resistance (solution resistance, $R_{s}$ ). In the intermediate frequency region $(1000$ to $10 \mathrm{~Hz})$, the capacitive behavior of the passive oxide and its dielectric properties can be observed. In general, the spectra display a linear slope in $\log |Z|$ as $\log (f)$ decreases, and the maximum phase angle is reached, and, finally, in the low frequency region $(f<10 \mathrm{~Hz})$ is possible to detect a horizontal line (low frequency plateau with the phase angle approaching $0^{\circ}$ ) for charge-transfer processes or a deviation from the behavior described for other relaxation processes (mass transfer, adsoption, etc.) taking place at the film-electrolyte interface or into the pores of the surface film. The basic elements that could be observed from Bode diagrams are resistors $R$ (high and low frequencies plateaus), in which $|Z|=R$ and the phase angle is approaching $0^{\circ}$, capacitors $C$, in which $\log |Z|$ is a straight line with a -1 slope and the phase angle is approaching $90^{\circ}$, and elements associated with diffusion, in which $\log |Z|$ has a -0.5 slope and the phase angle is approaching $45^{\circ}$. This mode of interpretation of the impedance spectra is very useful in order to define reliably the equivalent circuits of the system. 
Based on this Bode plot it can be observed again that the behavior of copper and bimetallic alloys is very similar. However, from the phase angle-frequency relationship, one can deduce the presence of three time constants (three maximums of phase angle). One of them is at the highintermediate frequency region (phase angle approaching $0^{\circ}$ and formation of the plateau at higher frequencies than $10,000 \mathrm{~Hz}$ ) with a maximum phase angle of $53-58^{\circ}$ at $300-$ $400 \mathrm{~Hz}$. This indicates that the time constant for the three materials has very similar characteristics and may correspond to the presence of a viscous film onto material surface $[13,14]$, and this may be associated with the formation of hydrides or metallic oxyhydrides as has been previously reported $[4,5$, $7,11]$. The second time constant is observed in the region of intermediate-low frequency, where for the bimetallic alloys the maximum phase angle is located approximately $10 \mathrm{~Hz}$ and for copper around $2 \mathrm{~Hz}$, in addition the phase angle is less in the case of copper $\left(45^{\circ}\right)$ compared to those of the bimetallic alloys (above $50^{\circ}$ ), and, on the other hand, the slope of the log $|Z|-f$ relationship is smaller for the case of copper and similar in the case of the bimetallic alloys. These features indicate susceptibility to corrosion of materials in artificial sweat, that is, phase angle values smaller than $90^{\circ}$ and slopes smaller than -1 , and it means that the protective layer is not an effective insulating barrier and is permeable to ions from solution [18]. Finally, in the low frequency region the third time constant is observed, $f<0.1 \mathrm{~Hz}$; however the phase angle does not tend to zero degrees and the plateau region is not developed. This behavior can be associated with mass transfer processes (diffusion) due to the presence of the viscous film defined by the first time constant $[13,19]$.

Liang et al. [7] have shown that the main corrosion products developed on a $\mathrm{Cu} 30 \mathrm{Zn}$ alloy immersed in artificial sweat are copper chloride hydroxide $\left(\mathrm{Cu}_{2}(\mathrm{OH})_{3} \mathrm{Cl}\right)$ and cuprous oxide $\left(\mathrm{Cu}_{2} \mathrm{O}\right)$. Then it is possible that $\mathrm{Zn}$-based corrosion products are completely soluble in the electrolyte. Similar observations have been reported for $\mathrm{Cu}$-based alloys evaluated in artificial sweat, further indicating that copper chloride hydroxide $\left(\mathrm{Cu}_{2}(\mathrm{OH})_{3} \mathrm{Cl}\right)$ is almost insoluble, in contrast to $\mathrm{CuCl}_{2} \cdot 2 \mathrm{H}_{2} \mathrm{O}$, which is very soluble [5]. Moreover, apparently the presence of nickel into alloy does not significantly improve its corrosion resistance, because Ni-based corrosion products formed are soluble in the electrolyte [11]. It has been reported that the amount of dissolved $\mathrm{Ni}$ is twice that of dissolved $\mathrm{Cu}$, and, however, the amount of dissolved $\mathrm{Zn}$ is similar to that of dissolved $\mathrm{Cu}[4]$.

Figure 6 shows the impedance spectra for copper and ternary alloys in the Nyquist and Bode format after 24 hours of immersion in artificial sweat at $37^{\circ} \mathrm{C}$. Analysis of the plots shows similar characteristics in all spectra, and the main differences are the diameter of the capacitive semicircles and the magnitude of the impedance module at low frequency region; this is apparently a function of alloy composition. Furthermore, from the phase angle-frequency relationship the presence of three time constants is also observed. The time constant observed in high-intermediate frequency region shows important differences; that is, the maximum phase angle of the ternary alloys is smaller than that observed for copper. This may indicate that the addition of $\mathrm{Zn}$ and $\mathrm{Ni}$ influences the corrosion resistance of the alloy, and this is a function of the $\mathrm{Zn} / \mathrm{Ni}$ ratio added. The interpretation of the three time constants has the same meaning described for those of the bimetallic alloys. It has also been shown that the main corrosion products formed onto $\mathrm{Cu}$-base ternary alloys are copper chloride hydroxide $\left(\mathrm{Cu}_{2}(\mathrm{OH})_{3} \mathrm{Cl}\right)$ and cuprous oxide $\left(\mathrm{Cu}_{2} \mathrm{O}\right)[4,5,7,11]$. The presence of both $\mathrm{Zn}$ - and $\mathrm{Ni}$-based corrosion products is rarely detected because their corrosion products are soluble in the electrolyte, and the presence of chloride ions breaks down the passivation layer; in $\mathrm{Cu}-\mathrm{Zn}-\mathrm{Ni}$ alloys, the concentration of dissolved $\mathrm{Ni}$ is the highest one [11]. Therefore, it might be expected that increasing the concentration of nickel in the ternary alloy increases its corrosion rate. $\mathrm{Cu}-, \mathrm{Zn}$-, and Ni-based soluble corrosion products are formed according to [5]

$$
\begin{gathered}
\mathrm{Zn}+(\mathrm{OH})_{\mathrm{ads}}{ }^{-} \longleftrightarrow \mathrm{ZnO}+\mathrm{H}^{+}+\mathrm{e}^{-} \\
\mathrm{Zn}+4 \mathrm{Cl}_{\mathrm{ad}}^{-} \longleftrightarrow \mathrm{ZnCl}_{4}{ }^{-}+2 \mathrm{e}^{-} \\
\mathrm{Ni}\left(\mathrm{H}_{2} \mathrm{O}\right)_{\mathrm{ad}} \longleftrightarrow \mathrm{Ni}(\mathrm{OH})_{\mathrm{ad}}+\mathrm{H}_{\mathrm{aq}}{ }^{+}+\mathrm{e}^{-} \\
\mathrm{Ni}\left(\mathrm{H}_{2} \mathrm{O}\right)_{\mathrm{ad}}+\mathrm{Cl}^{-} \longleftrightarrow \mathrm{Ni}(\mathrm{ClOH})_{\mathrm{ad}}{ }^{-}+\mathrm{H}^{+}+\mathrm{e}^{-} \\
\mathrm{Ni}(\mathrm{OH})_{\mathrm{ad}}+\mathrm{H}^{+}+\mathrm{e}^{-} \longleftrightarrow \mathrm{Ni}_{\mathrm{aq}}{ }^{2+}+\left(\mathrm{H}_{2} \mathrm{O}\right)_{\mathrm{ad}}+\mathrm{e}^{-} \longleftrightarrow \mathrm{Ni}(\mathrm{OH})_{2} \\
\mathrm{Cu}+2 \mathrm{Cl}^{-} \longleftrightarrow \mathrm{CuCl}_{2}{ }^{-}+\mathrm{e}^{-}
\end{gathered}
$$

On the other hand, corrosion performance of the $2 \mathrm{Ni} 6 \mathrm{Al}$ alloy was better than that of both $13 \mathrm{Ni15Zn}$ and $15 \mathrm{Ni} 22 \mathrm{Zn}$ alloys. This best performance can be associated with the formation of $\mathrm{Al}^{+}$ions (metal/oxide interface) and their migration (oxide/solution interface) to be oxidized to $\mathrm{Al}^{3+}$ according to the following $[13,20]$ :

$$
\begin{aligned}
\mathrm{Al}+\mathrm{H}_{2} \mathrm{O} & \longleftrightarrow \mathrm{AlOH}_{\mathrm{ads}}+\mathrm{H}^{+}+\mathrm{e} \\
\mathrm{AlOH}_{\mathrm{ads}} & \longrightarrow \mathrm{Al}(\mathrm{OH})^{+}+\mathrm{e} \\
\mathrm{Al}(\mathrm{OH})^{+}+5 \mathrm{H}_{2} \mathrm{O}+\mathrm{H}^{+} & \longleftrightarrow \mathrm{Al}^{3+}+6 \mathrm{H}_{2} \mathrm{O}+\mathrm{e}
\end{aligned}
$$

However, Al-based corrosion products are soluble in the electrolyte, and, on the other hand, in the presence of halides, the $\mathrm{Al}_{2} \mathrm{O}_{3}$ is frequently subjected to breakdown $[12,13]$.

Figure 7 shows the impedance spectra for copper and quaternary alloys in Nyquist and Bode format after 24 hours of immersion in artificial sweat at $37^{\circ} \mathrm{C}$. Again it is observed that the impedance spectra are very similar to those observed for copper and alloys both binary and ternary. In this case it is observed that the diameter of the capacitive semicircle as the magnitude of the impedance module at low frequency region of the ternary alloys is greater than those observed for copper. In addition, from the phase angle-frequency relationship the presence of three time constants with identical features is also observed. The corrosion resistance of these alloys was greater than the others previously described. Although the 13Zn6Mn4Ni alloy contains a high percentage of $\mathrm{Zn}$ and an appreciable amount of $\mathrm{Ni}$, its performance was better than that of copper. This may be due to the presence of $\mathrm{Mn}$ since it is known that the addition of this element increases the pitting corrosion resistance in chloride-rich electrolytes [21]. 

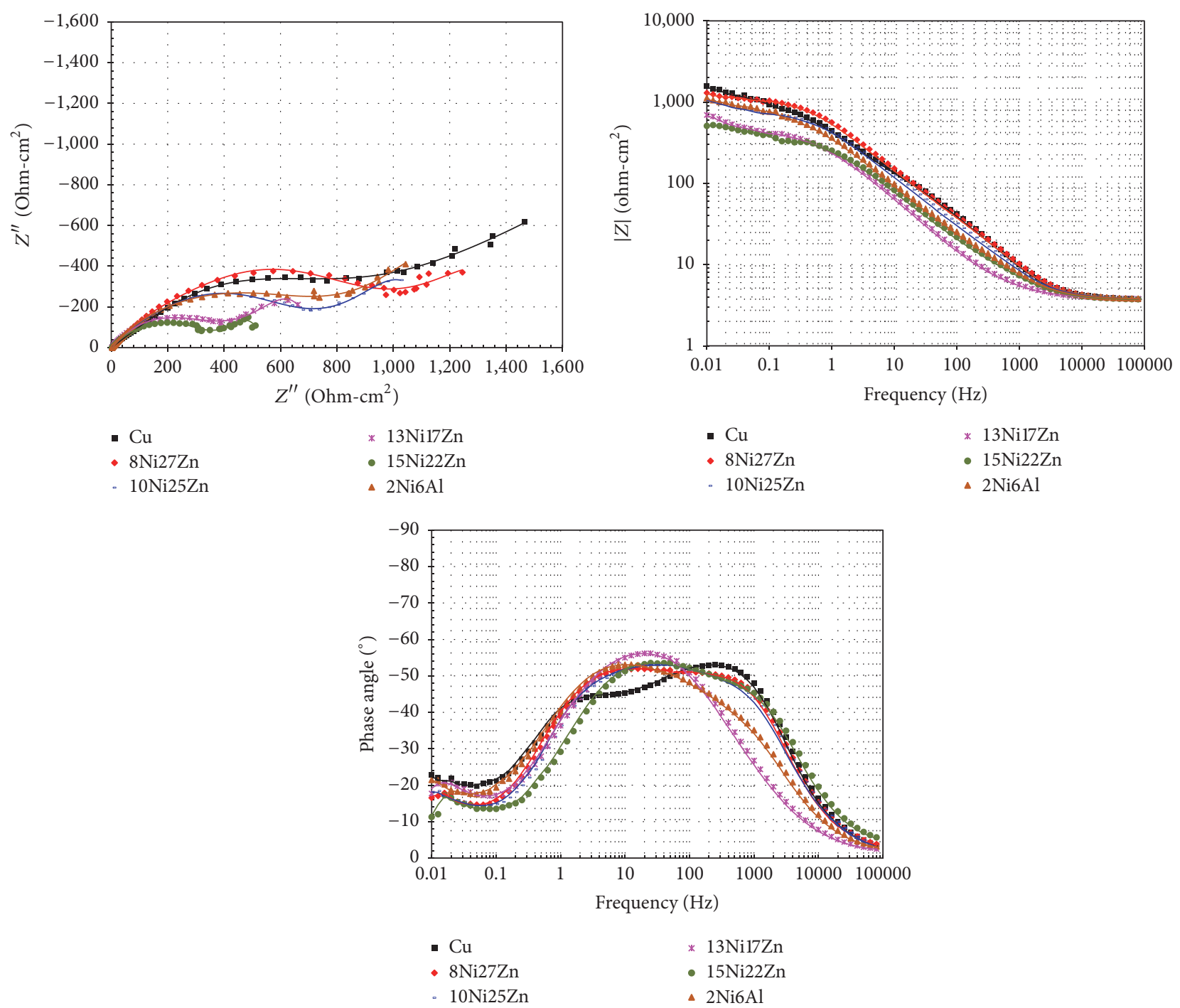

Figure 6: Nyquist and Bode plots for the $\mathrm{Cu}$-based ternary alloys in artificial sweat at $37^{\circ} \mathrm{C}$ after 24 hours. Points are the experimental data, and the continuous lines are the fitting data.

On the other hand, 6Zn5Al1Sn alloy showed similar behavior to that of $13 \mathrm{Zn} 6 \mathrm{Mn} 4 \mathrm{Ni}$ alloy, and this may indicate that the aluminum addition enhances the corrosion performance of the alloy, contrary to that observed with the addition of nickel.

Based on that discussed above, it is possible to establish that the equivalent circuit shown in Figure 8 is suitable for modeling the electrochemical behavior of the $\mathrm{Cu}$-based coins tested in artificial sweat at $37^{\circ} \mathrm{C}$. Because in the impedance spectra (Figures 5-7) a nonideal frequency response was evident, a constant phase element (CPE) was used in the equivalent circuit. Typically, a CPE is used to compensate for surface irregularities such as roughness or nonuniform distribution of charge transfer. Its impedance value is a function of the frequency and the phase is independent of the frequency:

$$
Z_{\mathrm{CPE}}=\frac{1}{Q(j \omega)^{n}}
$$

$Q$ is a proportional factor which combines properties related to the surface and electroactive species, and it is independent of the frequency; $j$ is imaginary number $(\sqrt{-1}) ; \omega$ is the angular frequency $(\omega=2 \pi f), f$ being the frequency; and $n$ is related to the slope of the $\log |Z|$ versus log $f$ plot. If $n$ is equal to 1 , the CPE is an ideal capacitor, where $Q$ is equal to the capacitance; however, if $0.5<$ $n<1$ then the CPE describes a distribution of dielectric relaxation times in frequency space, and if $n=0.5$ then the CPE represents a Warburg impedance with diffusional character.

As discussed previously, the impedance spectra indicate the presence of three time constants. The first time constant represents the surface layer (rich in copper chloride hydroxide and/or metallic hydroxides) through which the metal ions diffuse, the second time constant represents the chargetransfer process of the metal dissolution or the oxide dissolution, and the third one represents the diffusional effects due to the presence of the surface layer. From equivalent circuit, $Q_{f}$ 

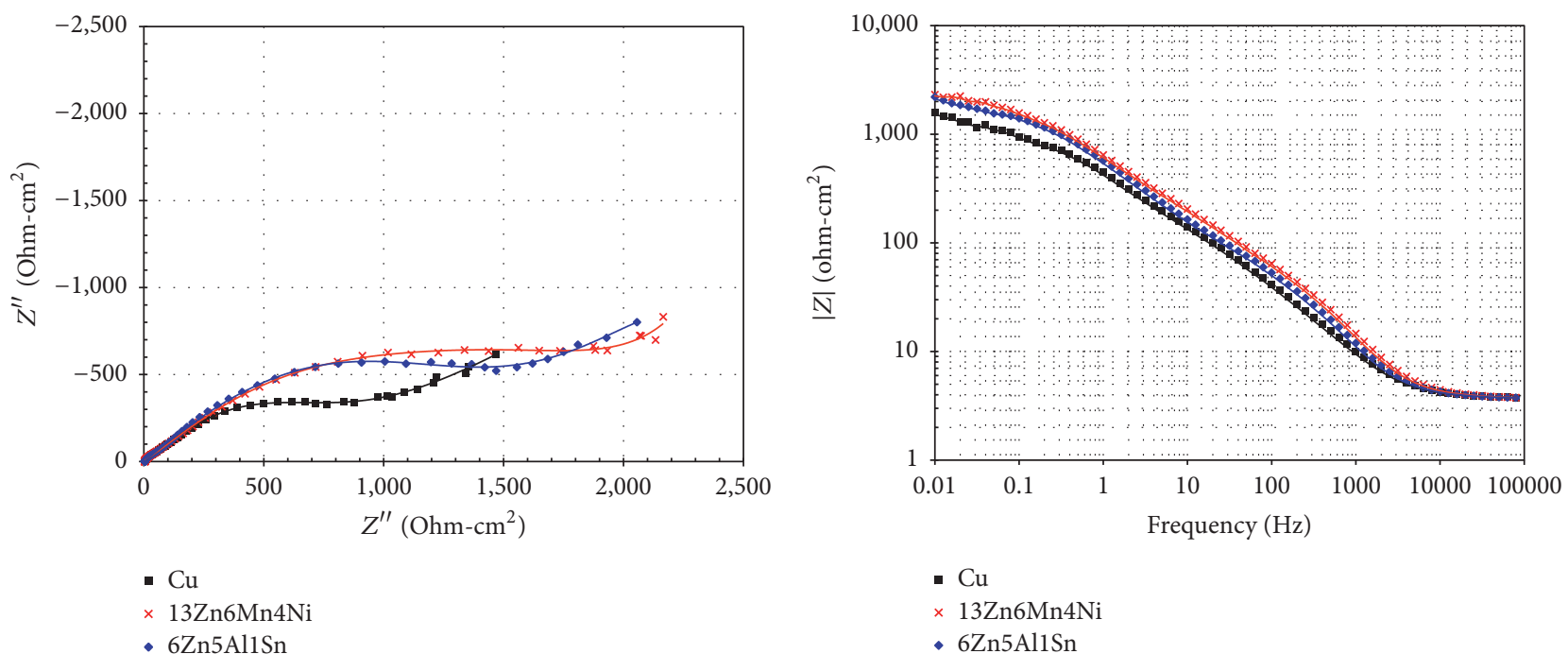

$\times 13 \mathrm{Zn} 6 \mathrm{Mn} 4 \mathrm{Ni}$

$\times 13 \mathrm{Zn} 6 \mathrm{Mn} 4 \mathrm{~N}$

- 6Zn5Al1Sn

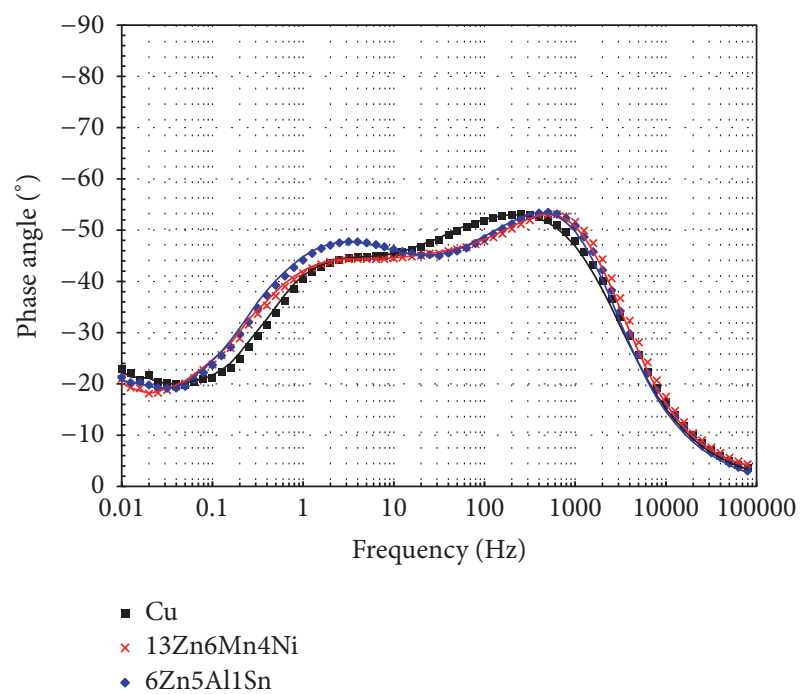

Figure 7: Nyquist and Bode plots for the Cu-based quaternary alloys in artificial sweat at $37^{\circ} \mathrm{C}$ after 24 hours. Points are the experimental data, and the continuous lines are the fitting data.

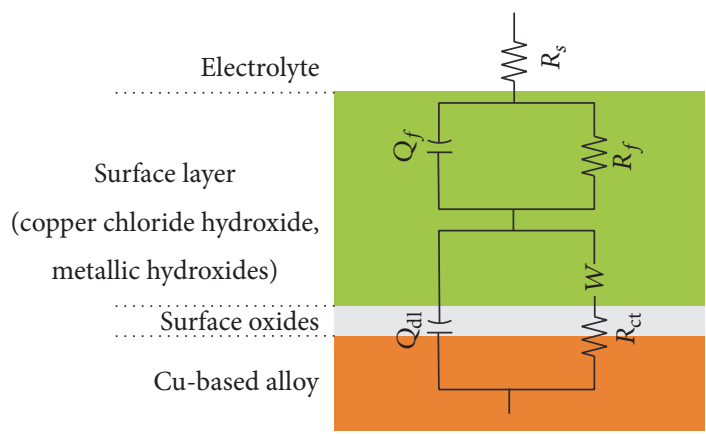

FIGURE 8: Equivalent circuit for $\mathrm{Cu}$-based coins evaluated in artificial sweat at $37^{\circ} \mathrm{C}$.

represents the CPE of the surface layer, $R_{f}$ is the resistance of the surface layer, $Q_{\mathrm{dl}}$ represents the CPE of the double layer capacitor, $R_{\text {ct }}$ is the resistance to the charge transfer, and $W$ is the element for the finite length Warburg (FLW) diffusion.

$$
Z_{W}=\frac{R_{W} * \tanh \left([\sqrt{-1} * T * \omega]^{P}\right)}{(\sqrt{-1} * T * \omega)^{P}},
$$

where $T=L^{2} / D, L$ is the effective diffusion thickness, $D$ is the effective diffusion coefficient, and $P=0.5$. The impedance spectra were modeled with the Zview software. The evolution of the main fitting parameters obtained is presented in Figures 9 and 10.

Figure 9 shows the variation of $R_{\mathrm{ct}}$ and $R_{f}$ for $\mathrm{Cu}$-based coins evaluated in artificial sweat at $37^{\circ} \mathrm{C}$. From $R_{\mathrm{ct}}$ plot it can be seen that both alloys, $13 \mathrm{Ni17Zn}$ and $15 \mathrm{Ni} 22 \mathrm{Zn}$, showed the lowest corrosion resistance, and the corrosion resistance of the quaternary alloys (13Zn6Mn4Ni and 6Zn5AllSn) was greater. On the other hand, $R_{f}$ values observed are lower with respect to those of $R_{\mathrm{ct}}$. This is consistent because $R_{f}$ 

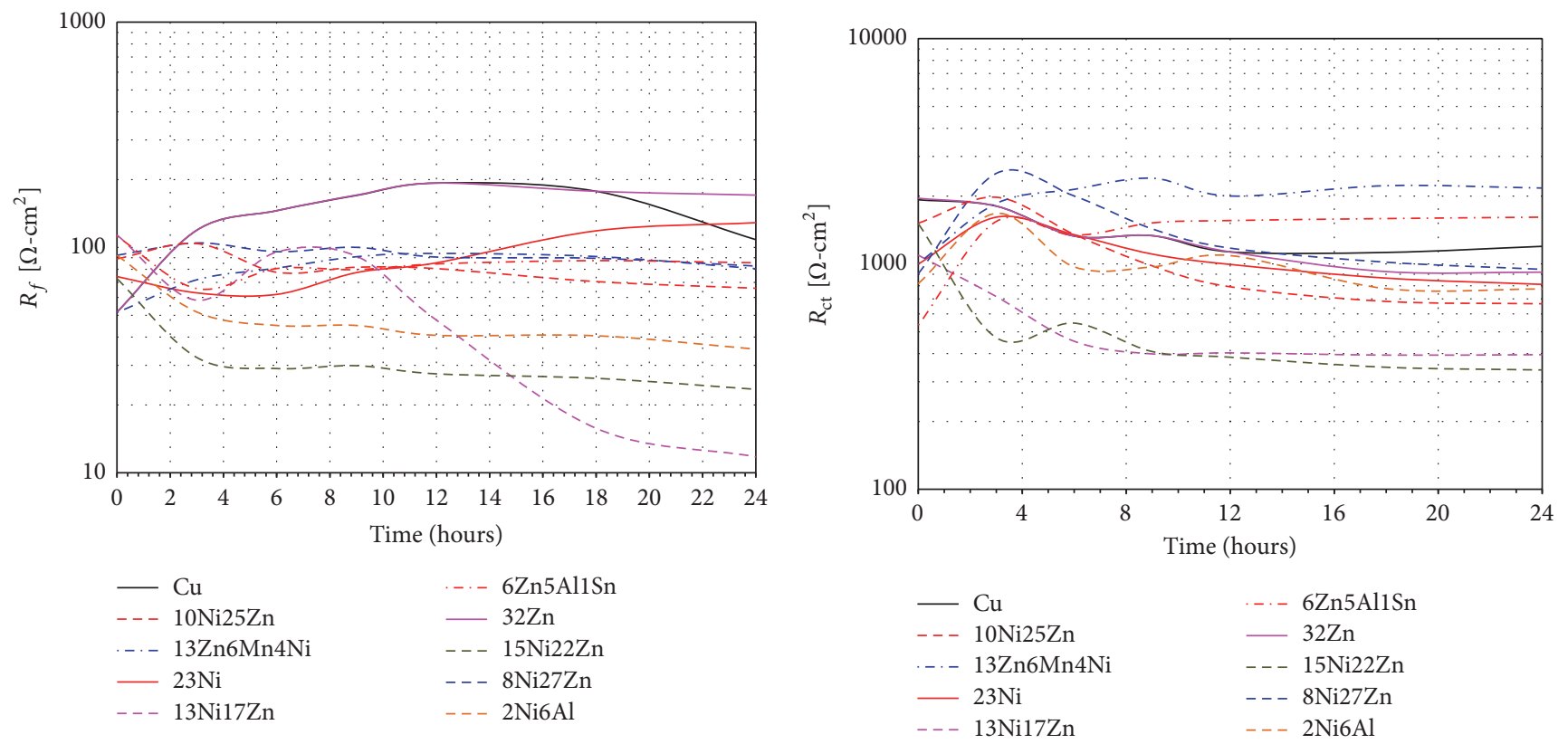

Figure 9: $R_{\mathrm{ct}}$ and $R_{f}$ variation against time for $\mathrm{Cu}$-based coins evaluated in artificial sweat at $37^{\circ} \mathrm{C}$.
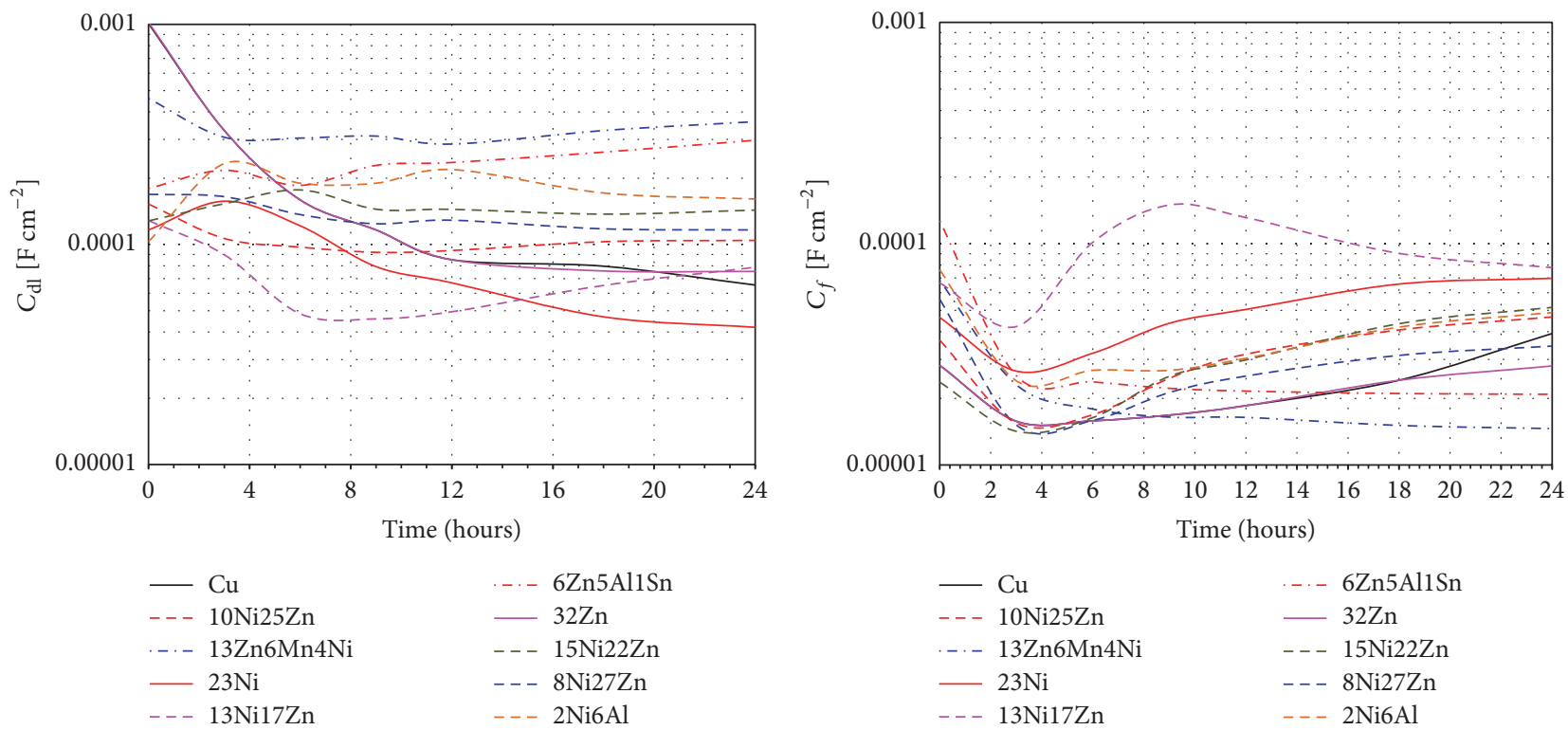

FIGURE 10: $C_{\mathrm{dl}}$ and $C_{f}$ variation against time for $\mathrm{Cu}$-based coins evaluated in artificial sweat at $37^{\circ} \mathrm{C}$.

represents the resistance of the surface layer through which the metal ions diffuse.

Figure 10 shows plots of the capacitance $\left(C_{\mathrm{dl}}\right.$ and $\left.C_{f}\right)$ versus time for $\mathrm{Cu}$-based coins evaluated in artificial sweat at $37^{\circ} \mathrm{C}$. Capacitance values were obtained from $Q$ values according to the following equation:

$$
C_{i}=\left(Q_{i} R_{i}^{\left(1-n_{i}\right)}\right)^{1 / n_{i}} .
$$

Values of $C_{f}$ are slightly lower than those of $C_{\mathrm{dl}}$. For $\mathrm{Cu}$ and bimetallic alloys, $C_{\mathrm{dl}}$ values tend to decrease, and at the same time their $C_{f}$ values tend to increase. For the others alloys both values of $C_{\mathrm{dl}}$ and $C_{f}$ remain almost constant. This behavior indicates a more active corrosion process both for $\mathrm{Cu}$ and for the bimetallic alloys.

Figure 11 shows the variation of $I_{\text {corr }}$ values versus time for the $\mathrm{Cu}$-based coins evaluated in artificial sweat at $37^{\circ} \mathrm{C}$. $I_{\text {corr }}$ values were calculated from $R_{\text {ct }}$ values obtained during the modeling process of the impedance spectra, using the same procedure as that employed from LPR values. It can be observed that both the performance ranking and $I_{\text {corr }}$ values are similar to those observed from LPR measurements (Figure 4). This indicates that the proposed equivalent circuit is 


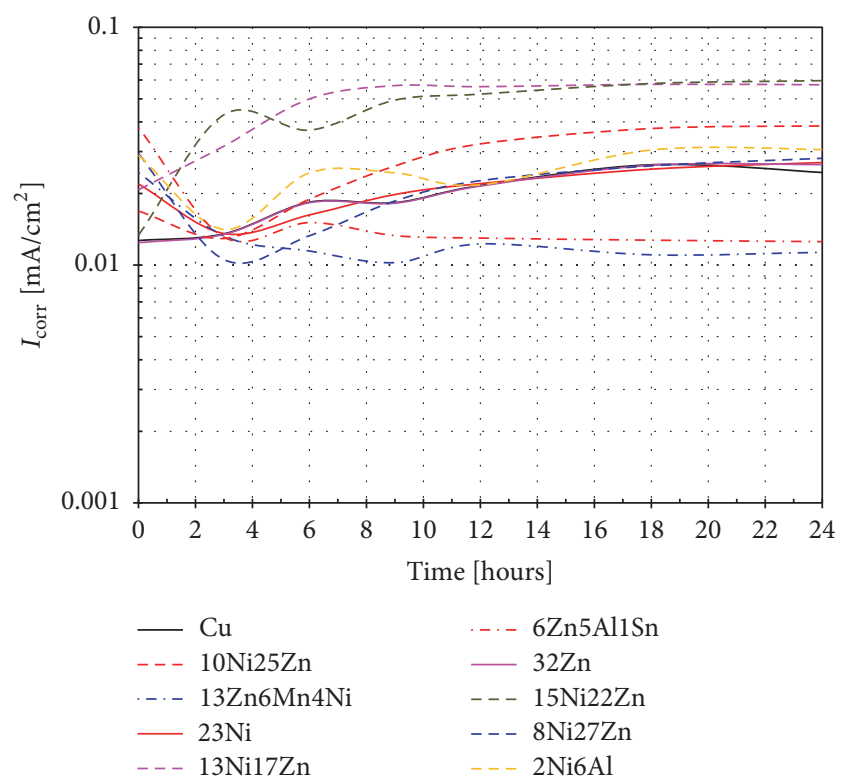

FIGURE 11: $I_{\text {corr }}$ variation against time for Cu-based coins evaluated in artificial sweat at $37^{\circ} \mathrm{C}\left(I_{\text {corr }}\right.$ values from $R_{\mathrm{ct}}$ values of EIS measurements).

suitable to simulate the impedance spectra and is compatible with the surface processes described above.

Binary alloys have a similar behavior to that observed for copper. Apparently the corrosion resistance of the ternary alloys (mainly the Ni-Zn-Cu ones) depends on the $\mathrm{Zn} / \mathrm{Ni}$ ratio, such that decreasing this value decreases the corrosion resistance of the alloy. Although the $\mathrm{Zn}$ is the the most electronegative element, its presence does not cause a detrimental effect as that observed by the presence of $\mathrm{Ni}$; this could be due to the high solubility of the Ni-based corrosion products. Again it is observed that the $13 \mathrm{Zn} 6 \mathrm{Mn} 4 \mathrm{Ni}$ quaternary alloy showed the best performance. It appears that the presence of $\mathrm{Mn}$ improved its corrosion performance, regardless of whether the $\mathrm{Zn} / \mathrm{Ni}$ ratio was similar to that of the $8 \mathrm{Ni27Zn}$ alloy. In the case of the $2 \mathrm{Ni} 6 \mathrm{Al}$ ternary and $6 \mathrm{Zn} 5 \mathrm{AllSn}$ quaternary alloys, both have a similar aluminum content; however their corrosion performance was different; again it appears that high corrosion rate of the ternary alloy was due to its $\mathrm{Ni}$ content. These observations indicate that nickel has a detrimental effect because it increases the corrosion rate of $\mathrm{Cu}$-based coins, and this is due to the formation of soluble $\mathrm{Ni}$-based corrosion products which cause defect points in the protective layer. Also, this may increase the risk to the health of people allergic to $\mathrm{Ni}$.

\section{Conclusions}

The corrosion performance of $\mathrm{Cu}$-based coins in artificial sweat was studied by potentiodynamic polarization curves, linear polarization resistance, and electrochemical impedance spectroscopy. The main results showed that the polarization curves of pure copper and $\mathrm{Cu}$-based coins are similar, suggesting that the main corrosion mechanism is the same, regardless of the number of alloying elements.
It was found that the impedance spectra are very similar, again regardless of the number of alloying elements; however, the main differences were the diameter of the capacitive semicircles and the magnitude of the impedance module at low frequency region. Impedance spectra indicated the presence of three time constants, where the first one represents a surface layer (rich in copper chloride hydroxide and/or metallic hydroxides) through which the metal ions diffuse, the second one represents the charge-transfer process (metal dissolution or the oxide dissolution), and the third one represents the diffusional effects due to the presence of the surface layer. The agreement of the obtained results of modeling of the impedance spectra with those of the linear polarization resistance measurements indicates that the proposed equivalent circuit is compatible with the surface processes described. In general, binary alloys have a similar performance as copper; however, corrosion resistance of ternary alloys depends on the $\mathrm{Zn} / \mathrm{Ni}$ ratio and by increasing the $\mathrm{Ni}$ content increases the corrosion rate. Ni causes a detrimental effect due to the high solubility of the Nibased corrosion products. Quaternary alloys showed the best performance; results showed that the Mn enhanced the corrosion performance and that the $\mathrm{Al}$ addition does not cause a negative effect as that observed by the $\mathrm{Ni}$ addition.

\section{Competing Interests}

The authors declare that there is no conflict of interests regarding the publication of this paper.

\section{Acknowledgments}

Financial support from Consejo Interinstitucional de Ciencia y Tecnología (CONACYT, México) (Projects 196205, 159898 , and 159913) is gratefully acknowledged. The authors acknowledge the support of I. S. Arizmendi-Carbajal and E. Y. Bautista-Flores (Universidad Politécnica del Estado de Morelos).

\section{References}

[1] R. J. Rathish, S. Rajendran, J. L. Christy et al., "Corrosion behaviour of metals in artificial sweat," The Open Corrosion Journal, vol. 3, no. 1, pp. 38-44, 2010.

[2] I. Rezić, L. Ćurković, and M. Ujević, "Study of microstructure and corrosion kinetic of steel guitar strings in artificial sweat solution," Materials and Corrosion, vol. 61, no. 6, pp. 524-529, 2010.

[3] Y. W. Song, D. Y. Shan, and E. H. Han, "Corrosion behaviors of electroless plating Ni-P coatings deposited on magnesium alloys in artificial sweat solution," Electrochimica Acta, vol. 53, no. 4, pp. 2009-2015, 2007.

[4] I. Milošev and T. Kosec, "Metal ion release and surface composition of the $\mathrm{Cu}-18 \mathrm{Ni}-20 \mathrm{Zn}$ nickel-silver during 30 days immersion in artificial sweat," Applied Surface Science, vol. 254, no. 2, pp. 644-652, 2007.

[5] I. Milošev and T. Kosec, "Study of Cu-18Ni-20Zn Nickel Silver and other $\mathrm{Cu}$-based alloys in artificial sweat and physiological 
solution," Electrochimica Acta, vol. 52, no. 24, pp. 6799-6810, 2007.

[6] N. Fredj, J. S. Kolar, D. M. Prichard, and T. D. Burleigh, "Study of relative color stability and corrosion resistance of commercial copper alloys exposed to hand contact and synthetic hand sweat," Corrosion Science, vol. 76, pp. 415-423, 2013.

[7] C.-H. Liang, S.-S. Wang, N.-B. Huang, and P. Wang, "Corrosion behavior of brass coinage in synthetic sweat solution," Transactions of Nonferrous Metals Society of China, vol. 25, no. 2, pp. 654-660, 2015.

[8] M. L. Mendoza-López, J. J. Pérez-Bueno, and M. E. RodríguezGarcía, "Characterizations of silver alloys used in modern Mexican coins," Materials Characterization, vol. 60, no. 9, pp. 10411048, 2009.

[9] ISO, "Watch-cases and accessories: gold alloy covering-part 2: determination of fineness, thickness, corrosion resistance, and adhesion," ISO 3160-2:2003, International Organization for Standardization (ISO), Geneva, Switzerland, 2003.

[10] D. J. Horton, H. Ha, L. L. Foster, H. J. Bindig, and J. R. Scully, "Tarnishing and $\mathrm{Cu}$ ion release in selected copper-base alloys: implications towards antimicrobial functionality," Electrochimica Acta, vol. 169, pp. 351-366, 2015.

[11] S. Colin, E. Beche, R. Berjoan, H. Jolibois, and A. Chambaudet, "An XPS and AES study of the free corrosion of $\mathrm{Cu}-, \mathrm{Ni}-$ and Zn-based alloys in synthetic sweat," Corrosion Science, vol. 41, no. 6, pp. 1051-1065, 1999.

[12] M. G. Mahjani, M. Sabzali, M. Jafarian, and J. Neshati, "An investigation of the effects of inorganic inhibitors on the corrosion rate of aluminum alloy using electrochemical noise measurements and electrochemical impedance spectroscopy," Anti-Corrosion Methods and Materials, vol. 55, no. 4, pp. 208216, 2008.

[13] J. Porcayo-Calderon, R. A. Rodriguez-Diaz, E. Porcayo-Palafox, J. Colin, A. Molina-Ocampo, and L. Martinez-Gomez, "Effect of $\mathrm{Cu}$ addition on the electrochemical corrosion performance of $\mathrm{Ni}_{3} \mathrm{Al}$ in $1.0 \mathrm{M} \mathrm{H}_{2} \mathrm{SO}_{4}$," Advances in Materials Science and Engineering, vol. 2015, Article ID 209286, 18 pages, 2015.

[14] S. Godavarthi, J. Porcayo-Calderon, E. Vazquez-Velez, M. Casales-Diaz, D. M. Ortega-Toledo, and L. Martinez-Gomez, "Influence of the chemical composition in the electrochemical response of permanent magnets," Journal of Spectroscopy, vol. 2015, Article ID 356027, 16 pages, 2015.

[15] J. Porcayo-Calderon, I. Regla, E. Vazquez-Velez et al., "Effect of the unsaturation of the hydrocarbon chain of fatty-amides on the $\mathrm{CO}_{2}$-corrosion of carbon steel using EIS and real-time corrosion measurement," Journal of Spectroscopy, vol. 2015, Article ID 184140, 10 pages, 2015.

[16] J. E. G. González and J. C. Mirza-Rosca, "Study of the corrosion behavior of titanium and some of its alloys for biomedical and dental implant applications," Journal of Electroanalytical Chemistry, vol. 471, no. 2, pp. 109-115, 1999.

[17] S. Tamilselvi, V. Raman, and N. Rajendran, "Corrosion behaviour of Ti-6Al-7Nb and Ti-6Al-4V ELI alloys in the simulated body fluid solution by electrochemical impedance spectroscopy," Electrochimica Acta, vol. 52, no. 3, pp. 839-846, 2006.

[18] F. Matemadombo and T. Nyokong, "Characterization of selfassembled monolayers of iron and cobalt octaalkylthiosubstituted phthalocyanines and their use in nitrite electrocatalytic oxidation," Electrochimica Acta, vol. 52, no. 24, pp. 6856-6864, 2007.

[19] J. Porcayo-Calderon, L. M. Martínez De La Escalera, J. Canto, and M. Casales-Diaz, "Imidazoline derivatives based on coffee oil as $\mathrm{CO}_{2}$ corrosion inhibitor," International Journal of Electrochemical Science, vol. 10, no. 4, pp. 3160-3176, 2015.

[20] J. Porcayo-Calderon, L. M. Martínez de la Escalera, J. Canto, M. Casales-Diaz, and V. M. Salinas-Bravo, "Effect of the temperature on the $\mathrm{CO}_{2}$-corrosion of $\mathrm{Ni}_{3} \mathrm{Al}$," International Journal of Electrochemical Science, vol. 10, no. 4, pp. 3136-3151, 2015.

[21] G. Rondelli, B. Vicentini, and A. Cigada, "Influence of nitrogen and manganese on localized Corrosion behaviour of stainless steels in chloride environments," Materials and Corrosion, vol. 46, no. 11, pp. 628-632, 1995. 

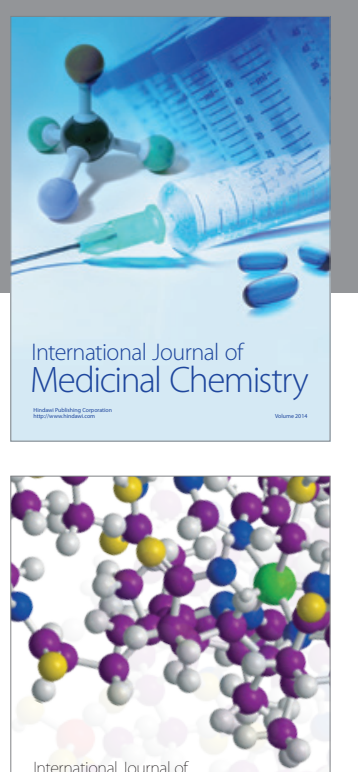

Carbohydrate Chemistry

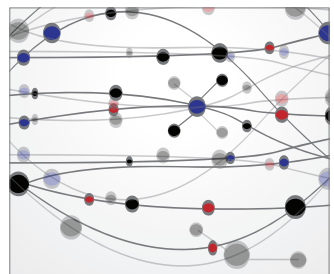

The Scientific World Journal
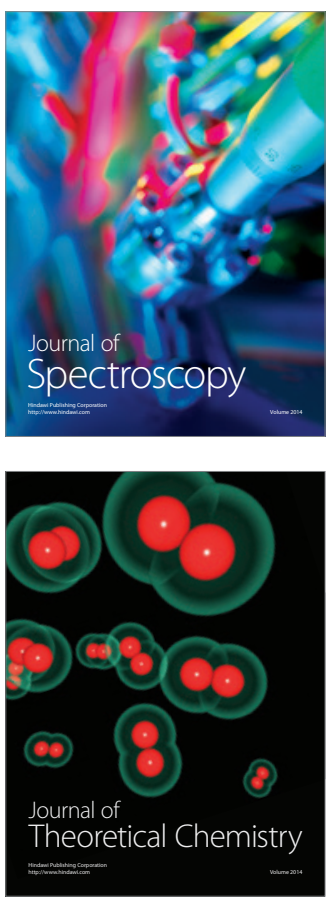
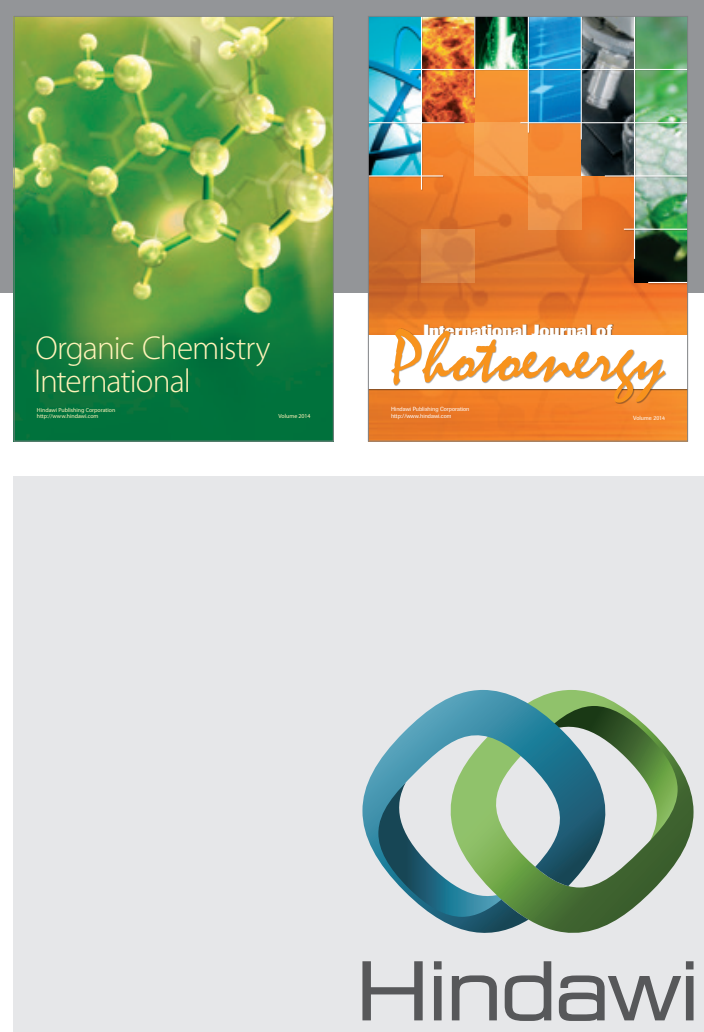

Submit your manuscripts at

http://www.hindawi.com

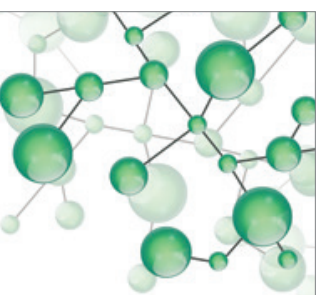

International Journal of

Inorganic Chemistry

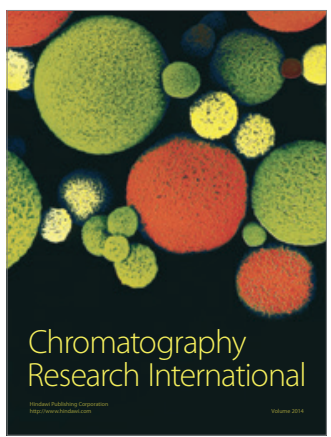

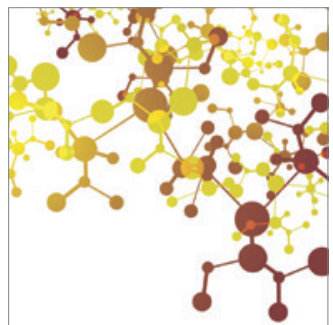

Applied Chemistry
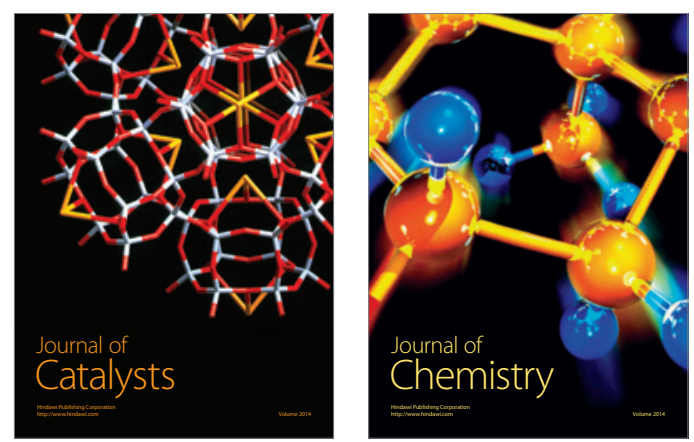
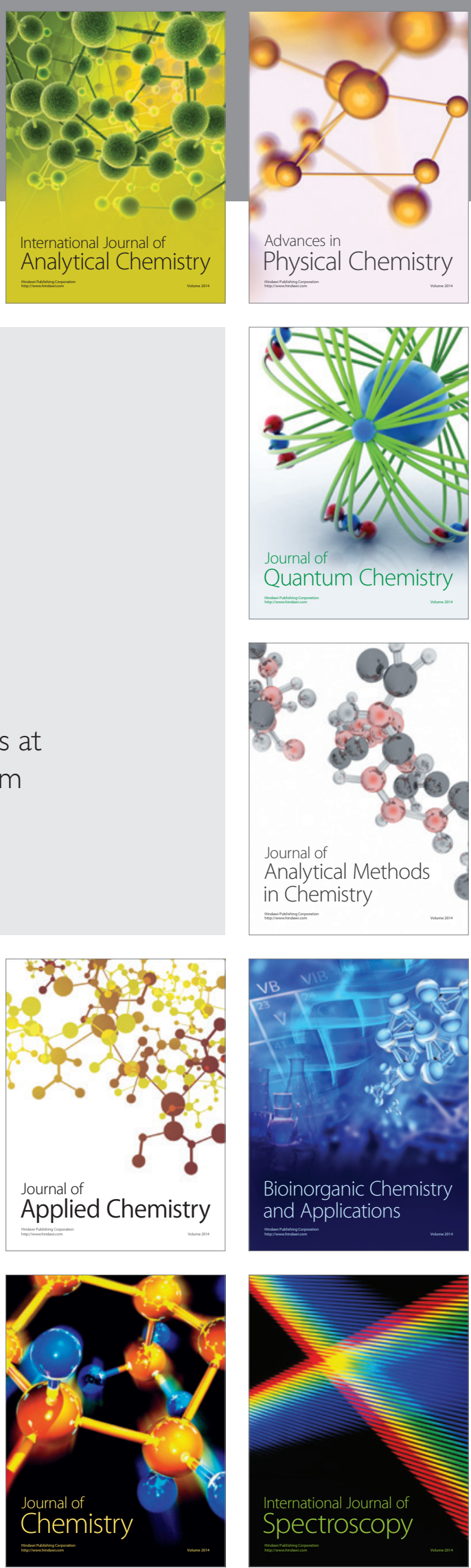